\title{
MULHERES OCUPANTES DE CARGOS ELETIVOS NO INTERIOR DO PARANÁ: CRUZEIRO DO OESTE - PR.
}

\author{
Ana Letícia Stori Mendes ${ }^{1}$ \\ Rafael Egidio Leal e Silva ${ }^{2}$
}

\begin{abstract}
Resumo: Este artigo tem por objetivo investigar a vivencia e participação feminina em cargos eletivos no município de Cruzeiro do Oeste, localizado no noroeste do Estado do Paraná, enfocando os tempos atuais. Este município foi fundado em 1952, e atualmente com cerca de 21.000 habitantes (sendo 16.375 eleitores em 2016) e sua investigação é interessante por indicar o panorama acerca da participação feminina na política em municípios menores. Nas últimas eleições, em 2016, foram eleitas 04 mulheres dentre as 11 cadeiras do legislativo local: Imaculada Conceição da Silva Magalhães, Aparecida Nunes Gonçalves, Nadya Correa Massé, Rosy Anne Almodovas Rodrigues. No caso do poder executivo local, duas vice-prefeitas foram eleitas na história deste município: Dayana Mazzer (2012-2016) e Maria Helena Bertocco Martins (2016), portanto, apenas nas duas últimas eleições há a presença de mulheres integrantes da chapa vencedora ao Executivo local. Sendo de extrema importância o estudo e uma análise aprofundada acerca da participação feminina na política, tendo em vista que em sociedades regidas por matrizes culturais atravessadas por relações assimétricas de gênero, é um desafio para as mulheres destacarem-se em um universo predominantemente masculino, como é a política. No contexto deste artigo, questionamos como se dá a vivência da mulher em municípios menores. Pressupondo que o funcionamento da democracia implica na representação equilibrada da sociedade, especialmente nos parlamentos, questionamos a percepção das mulheres em cargos políticos públicos do atual período acerca da participação feminina na política no contexto de Cruzeiro do Oeste, sendo realizadas entrevistas anônimas com as mulheres com roteiro aberto e cujo resultado é analisado neste artigo.
\end{abstract}

Palavras-chave: Política. Gênero. Mulheres. Cruzeiro do Oeste-PR.

\section{Women occupying elective positions in the interior of Paraná:}

\section{Cruzeiro do Oeste-PR.}

\begin{abstract}
This article aims to investigate the experience and participation of women in elective positions in the municipality of Cruzeiro do Oeste, located in the northwest of the State of Paraná, focusing on the current times. This municipality was founded in 1952, and currently has about 21,000 inhabitants (16,375 voters in 2016) and this research is interesting because it indicates the panorama about female participation in politics in smaller municipalities. In the last elections, in 2016, 04 women were elected from the 11 seats of the local legislature: Imaculada Conceição da Silva Magalhães, Aparecida Nunes Gonçalves, Nadya Correa Massé, Rosy Anne Almodovas Rodrigues. In the case of the local executive branch, two vice presidents were elected in the history of this municipality: Dayana Mazzer (2012-2016) and Maria Helena Bertocco Martins (2016), therefore, only in the last two elections were the presence of women members of the winning plaque to the local executive. Being extremely important the study and an in-depth analysis about the female participation in politics, considering that in societies governed by cultural matrices crossed by asymmetrical relations of gender, it is a challenge for the women to stand out in a predominantly male universe, as it's politics. In the context of this article, we question how women experience in smaller municipalities. Assuming that the functioning of democracy implies a balanced representation of society, especially in parliaments, we question the perception of women in public political positions of the current period about the participation of women in politics in the context of Cruzeiro do Oeste, anonymous interviews were conducted with women with an open script and the results are analyzed in this article.
\end{abstract}

\footnotetext{
${ }^{1}$ Aluna do Curso Técnico em Química Integrado ao Ensino Médio do Instituto Federal do Paraná - Campus Umuarama. E-mail de contato: ana.stori.lele@gmail.com .

2 Professor de Sociologia RSCIII do Instituto Federal do Paraná. Mestre em Psicologia. E-mail de contato: rafael.silva@ifpr.edu.br.
} 
Key words: Policy. Genre. Women. Cruzeiro do Oeste-PR.

*Recebido em 30/05/2018.

*Aceito em 12/06/2018.

Este artigo tem por objetivo investigar a vivência das representantes de cargos eletivos na cidade de Cruzeiro do Oeste-PR a partir das suas perspectivas e expectativas através de entrevistas, bem como analisar os fatores que podem influenciar nesta participação tendo em vista o desafio encontrado pelas mulheres para destacarem-se em um universo predominantemente masculino, principalmente vivendo em sociedades regidas por matrizes culturais atravessadas por relações assimétricas de gênero.

É consenso que a diferença entre os gêneros possui influências relevantes em nossa sociedade, não apenas no mercado de trabalho, e também interferindo diretamente em cargos representativos e/ou de lideranças políticas. Se nossa sociedade elegeu como signos de sua própria civilização a democracia representativa como governo social e o direito que pugna pela igualdade entre homens em mulheres, a sociedade brasileira ainda não materializou tais circunstâncias, efetivadas apenas na letra da lei. Assim, quais os obstáculos para a efetiva representatividade feminina nos cargos políticos eletivos brasileiros, na visão da própria mulher? Nosso objetivo é, portanto, investigar a fala de mulheres que se encontram na posição de representantes eleitas, enfocando um município com população inferior a trinta mil habitantes, caso de Cruzeiro do Oeste, localizado no noroeste do Estado do Paraná.

Histórica e socialmente, podemos considerar que a baixa representatividade feminina nos meios de poder deve-se a construção de uma representação de figura feminina e masculina vinda de muitos séculos no decurso civilizatório, onde o homem é o líder da casa, provedor da economia do lar, representando o espaço público da sociedade, enquanto a mulher está submissa a ele, sendo responsável pela casa, dos filhos, sendo a provedora do amor, relacionada então com o cenário privado da sociedade. Estes estereótipos concedidos as mulheres têm sido causador das inúmeras dificuldades por elas hoje enfrentadas, como o árduo trabalho para se encaixar no espaço público. A origem deste modelo existente na sociedade, a partir do estigma histórico da figura feminina, incapacitando-a de exercer e estar presente no meio político vem desta relação cultural, tem origens muito profundas na historicidade, conforme nos aponta Evelyn $\operatorname{Reed}^{3}$ (2008) a partir do texto clássico de Friedrich Engels ${ }^{4}$ (s.d.):

(...) como é que nossos progenitores haviam conseguido superar o passo inicial de primatas passando par a etapa de seres humanos? Em seu ensaio $O$ papel do trabalho na

\footnotetext{
${ }^{3}$ REED, E. Sexo contra sexo ou classe contra classe. São Paulo: Editora Instituto José Luís e Rosa Sundermann, 2008.

${ }^{4}$ ENGELS, F. A origem da família, da propriedade privada e do Estado. In: MARX, K. \& ENGELS, F. Obras escolhidas. São Paulo: Alfa Ômega, s.d. Vol. 03.
} 
transformação do macaco em homem, Engels explica que foi a atividade produtiva sistemática que converteu os antropoides em humanoides. Com essa explicação, Engels foi o primeiro a apresentar o que podemos chamar propriamente de "teoria do trabalho como origem da sociedade", e isto teve implicações muito importantes para a "questão da mulher". (REED, 2008, p. 27-28).

Nesta concepção, foi por intermédio da divisão social do trabalho, que a princípio foi a divisão sexual do trabalho, deu-se início a sociedade de classes, aquela onde uma parte da sociedade se reproduz a partir da exploração do trabalho da maior parte social. Muito embora o trabalho da mulher tenha sido tão relevante e produtivo que o dos homens, em nossas mentes encobertas pela ideologia que o gênero impõe lugares sociais, o espaço da mulher na sociedade ficou relegado ao doméstico. Essa ideologia é iniciada dentro de casa, portanto, onde geralmente possui uma ideologia patriarcal, em que os homens possuem o "Poder" do lar, enquanto a mulher possui as tarefas do lar. Assim, conforme Haraway 5: "Além do trabalho assalariado, a divisão de trabalho por gênero incluía também as categorias de trabalho excluídas e não historicizadas em Marx e Engels" (HARAWAY, 2004, p. 228), como a criação dos filhos, os cuidados com velhos e doentes, a cozinha, além da prostituição. Ou seja, a supremacia do macho, que sustenta sobre o mito de que as mulheres representam um sexo inferior, existe somente em na sociedade de classes de cunho patriarcal. Ana Alice Alcantara $\operatorname{Costa}^{6}$ contribui manifestando,

\begin{abstract}
Na perspectiva de atender aos objetivos teóricos de nosso estudo, consideramos que a questão básica da exclusão das mulheres da esfera pública está ligada ao conceito de cidadania. Um conceito construído através de toda a história do pensamento universal, a partir de um modelo masculino e voltado para os interesses dos homens, na medida em que refletem, em todos os processos históricos de sua constituição, a hierarquia sexual da sociedade, isto é, do patriarcado. (COSTA, 1998, p. 51).
\end{abstract}

Com isso foi sendo gerado o conceito de divisão, o qual hoje é visível em nosso corpo social. Mesmo com o passar de muitos anos, infelizmente a mulher ainda encontra barreiras nos cenários sociais, principalmente no que tange a participação de cargos eletivos tendo em vista que a desigualdade de gêneros no exercício do poder: ainda que as mulheres sejam mais da metade da população nacional, sua representatividade na política está muito aquém dos $50 \%$. A exclusão da mulher na vida política é um reflexo da exclusão da mulher na sociedade e na ausência de reconhecimento como sujeito, baseado em grande medida no predomínio da figura do homem, seja

\footnotetext{
${ }^{5}$ HARAWAY, D. Gênero" para um dicionário marxista: a política sexual de uma palavra. Cad. Pagu, Campinas, n. 22 , p. 201-246, 2004.

${ }^{6}$ COSTA, A. As donas no poder. Mulher e política na Bahia. Salvador: NEIM/UFBa -Assembleia Legislativa da Bahia, 1998. Col. Bahianas. Disponível em <http://www.neim.ufba.br/site/arquivos/file/donasnopoder.pdf>. Acesso em: 28/02/2018.
} 
no aspecto social, político ou econômico (VAZ $\left.{ }^{7}, 2008\right)$. Por isso não podemos deixar de considerar as barreiras sociais invisíveis que dificultam que a mulher se torne efetivamente uma agente política em igualdade de condições nas disputas eleitorais. Assim sendo, como a mulher percebe tal diferença, especialmente a ocupante de um cargo político local em um contexto interiorano? Esta mulher é também um agente de denúncia acerca do domínio masculino em seu município?

Questionamos então a importância da participação das mulheres em cargos políticos na cidade de Cruzeiro do Oeste, e quais são os fatores que influenciam para a pouca participação das mesmas nos cargos, a partir da análise da fala das mulheres em cargos eletivos nestas cidades. Em função disso, a mulher tem lutado para garantir seu espaço neste cenário, mesmo que para isso, tenha que se moldar, atribuindo algumas características a qual não a pertence para conquistar uma candidatura, por exemplo. Quanto a isso, Bourdieu ${ }^{8}$ afirma que:

Para chegar realmente a conseguir uma posição, uma mulher teria que possuir não só o que é explicitamente exigido pela descrição do cargo, como também todo um conjunto de atributos que os ocupantes masculinos atribuem usualmente ao cargo, uma estatura física ou aptidões, como a agressividade, a segurança, a 'distância em relação ao papel', a autoridade dita natural, etc., para as quais os homens foram preparados e treinados tacitamente enquanto homens. (BOURDIEU, 2010, p. 78)

Portanto, quando conquistam esses espaços, estão ocupando ainda as posições menos favorecidas, por exemplo, sendo embora verdade que as mulheres estão cada vez mais representadas em funções públicas, são sempre as posições mais baixas e mais precárias que lhes são reservadas, sendo este um alvo a ser analisado nos respectivos municípios.

É por esses impasses que são criadas as ações afirmativas, que se manifesta por exemplo na Lei 9504/1997 relacionada a inclusão feminina nas esferas públicas do poder, garantindo 30\% de vagas de candidaturas por gênero aos partidos. Essas ações configuram-se em uma medida que objetiva efetivar o que já é de direito da mulher, que é a igualdade em todas as instâncias, Barbosa Gomes $^{9}$ conceitua essa ação afirmativa destacando seu papel como de remediador.

As ações afirmativas se definem como políticas públicas (e privadas) voltadas à concretização do princípio constitucional da igualdade material e à neutralização dos

\footnotetext{
7 VAZ, G.A. A participação da mulher na política Brasileira: a lei de cotas. Monografia de Conclusão de Curso apresentada ao Curso de Especialização em Processo Legislativo do Centro de Formação, Treinamento e Aperfeiçoamento, da Câmara dos Deputados. 2008.

${ }^{8}$ BOURDIEU, P. A dominação masculina. 8.ed. Rio de Janeiro: Bertrand Brasil, 2010.

${ }^{9}$ BARBOSA GOMES, J. (S.D.) O debate constitucional sobre as ações afirmativas. Londrina-PR: Agência UEL de Notícias, s.d. Disponível em: <http://www.uel.br/com/noticiadigital/index.php?arq=ARQ_art\&FWS_Ano_Edicao=1\&FWS_N_Edicao $=1 \&$ FWS_Cod_Categoria=1\&FWS_N_Texto=3529 >.
} 
efeitos da discriminação racial, de gênero, de idade, de origem nacional e de compleição física. Na sua compreensão, a igualdade deixa de ser simplesmente um princípio jurídico a ser respeitado por todos, e passa a ser um objetivo constitucional a ser alcançado pelo Estado e pela sociedade. (BARBOSA GOMES, s.d.).

Ou seja, as ações afirmativas é um mecanismo de interferência (pública e privada) para garantir que grupos excluídos tenham acesso ao âmbito social, político e econômico. Porém a questão colocada aqui não é apenas a garantia de representatividade feminina no cenário político, decretada pela lei de cotas e sim a representatividade proporcional, uma vez que a democracia só poderá crescer com a participação igualitária das mulheres na política. Essa política de cotas instituída pela lei 9504/97 tem como objetivo incentivar a participação das mulheres no cenário político, no entanto, essa participação feminina na política é desigual a participação do homem, devido à falta de incentivo a essas mulheres, pois as cotas por si só não tem sido garantia da representação igualitária de mulheres e homens. Deste modo, perante a esta contradição tem-se como presunção que o cenário da mulher na perspectiva populacional está sendo um espaço de luta afim de que ganhem vez e voz.

\section{Cruzeiro do Oeste: panorama eleitoral}

A investigação em Cruzeiro do Oeste, localizada no Noroeste do Estado do Paraná, distante cerca de 150 quilômetros de Maringá e cerca de 600 quilômetros da capital Curitiba, é interessante pois podemos caracterizar o papel da mulher na política local em municípios menores. Fundada em 1952, e com população de 20.950 habitantes conforme censo de 2016 (SANTOS et alii, 2017, p. 06) e tem projeção de decréscimo de população para 20.011 habitantes em 2030, conforme dados do IPARDES (ibidem, p. 06), tendo tido 16.375 eleitores em 2016.

Podemos considerar que historicamente há uma baixa representatividade feminina na câmara local, uma vez que no período de 1955 até o ano 2004, foram as seguintes vereadoras eleitas na cidade: em 1972 (Solange Paiva Cardoso), em 1976 (Maria José Nobrega Gomes), em 1996 (Rose Cléia Cecconi Martins), em 2000 (Maria Helena Bertocco Martins) e em 2004 (Rose Cléia Cecconi Martins, novamente). Na legislatura de 2008 a 2012 não foram eleitas representantes femininas nesta câmara, a despeito dos incentivos governamentais na forma de ações afirmativas como comentado acima, especialmente da Lei n. 9504/1997, que impôs cotas de candidaturas para cada sexo aos partidos ou coligações.

No caso do poder executivo local, duas vice-prefeitas foram eleitas na história desta cidade: Dayana Mazzer (2012-2016) e Maria Helena Bertocco Martins (2016), portanto, apenas nas duas 
últimas eleições que este município teve a presença de mulheres integrantes da chapa vencedora ao Executivo local.

Na eleição de 2016, no entanto, foram eleitas 04 mulheres dentre as 11 cadeiras do legislativo local: Imaculada Conceição da Silva Magalhães, Aparecida Nunes Gonçalves, Nadya Correa Massé, Rosy Anne Almodovas Rodrigues, além da vice-prefeita supracitada, que já foi vereadora. Pode ser observado que a presença de quatro mulheres eleitas para ocupar o cargo de vereadora no município de Cruzeiro do Oeste, juntamente com a eleição de uma vice-prefeita, que mostra uma mudança significativa em relação aos anos passados, onde no período de 1955 a 2000 apenas quatro mulheres ocuparam o cargo de vereadora no município apenas em 2014 foi eleita uma representante na chapa do poder Executivo local. Em aproximadamente 63 anos de história o município contou com a participação de apenas duas vice-prefeitas, evidenciando a desigualdade de gênero existente na política onde a mulher tem muita dificuldade em ser bem vista. A baixa participação das mulheres na política não deve ser entendida como resultado de seu desinteresse ou apenas de um veto de gênero por parte dos partidos.

Para esta pesquisa, delimitamos o período e as entrevistadas, utilizamos como parâmetro as mulheres ocupantes das cadeiras públicas eletivas a partir do ano 2000. Desta forma, apenas a exvereadora Rose Cléia Cecconi Martins não foi entrevistada, uma vez que atualmente reside em Curitiba e não foi localizada para a participação na pesquisa. As entrevistas foram realizadas no segundo semestre do ano de 2017, portanto, em pleno exercício de mandato das vereadoras e da atual vice-prefeita, sendo que apenas Dayana Mazzer não está ocupando atualmente uma cadeira pública eletiva. Todas as entrevistas foram gravadas e foi assinado Termo de Consentimento Livre e Esclarecido, e serão apresentadas e discutidas anonimamente.

Para os fins desta pesquisa foi traçado o perfil das mulheres que ocupam cadeiras em cargos políticos locais, entre Câmara de Vereadores e a Prefeitura Municipal da cidade de Cruzeiro do Oeste, no interior do Paraná, o qual foi priorizado a idade, nível de instrução, estado civil, filhos, renda familiar mensal, nível de instrução pai/mãe e a religião. Através destes dados, podemos traçar um perfil médio sobre mulheres ocupantes em cargos públicos eletivos no município de Cruzeiro do Oeste. No tocante a tais relações, temos a seguinte tabela, ordenada a partir da idade das mulheres ocupantes em cargos públicos:

Tabela 1 - Perfil socioeconômico das Mulheres Ocupantes de Cargos eletivos públicos da atual legislatura de Cruzeiro do Oeste-PR

\begin{tabular}{l|c|c|c|c|c|c|c}
\hline Entrevistada & Idade & $\begin{array}{c}\text { Nível De } \\
\text { Instrução }\end{array}$ & $\begin{array}{c}\text { Estado } \\
\text { Civil }\end{array}$ & Filhos & $\begin{array}{c}\text { Renda } \\
\text { Familiar R\$ }\end{array}$ & $\begin{array}{c}\text { Nível De } \\
\text { Instrução } \\
\text { Pai/Mãe }\end{array}$ & Religiosidade \\
\hline
\end{tabular}




\begin{tabular}{c|c|c|c|c|c|c|c}
\hline A & 61 anos & Superior & Casada & 2 & $18.000,00$ & $\begin{array}{c}\text { Sem } \\
\text { escolarização }\end{array}$ & $\begin{array}{c}\text { Evangélica } \\
\text { praticante }\end{array}$ \\
\hline B & 58 anos & $\begin{array}{c}\text { Técnico em } \\
\text { Enfermagem }\end{array}$ & Casada & 3 & $1.500,00$ & $\begin{array}{c}\text { Sem } \\
\text { escolarização }\end{array}$ & $\begin{array}{c}\text { Católica não } \\
\text { praticante }\end{array}$ \\
\hline C & 54 anos & $\begin{array}{c}\text { Superior, } \\
\text { graduação em } \\
\text { adm. escolar }\end{array}$ & Viúva & 3 & $10.000,00$ & Analfabetos & $\begin{array}{c}\text { Evangélica } \\
\text { praticante }\end{array}$ \\
\hline D & 32 anos & $\begin{array}{c}\text { Especialização, } \\
\text { Professora }\end{array}$ & Casada & 3 & $13.000,00$ & Graduados & $\begin{array}{c}\text { Evangélica } \\
\text { praticante }\end{array}$ \\
\hline E & 35 anos & $\begin{array}{c}\text { Pós graduada } \\
\text { Ensino médio } \\
\text { completo }\end{array}$ & Casada & 1 & $9.000,00$ & $\begin{array}{c}\text { Graduados } \\
\text { Protestante } \\
\text { praticante }\end{array}$ \\
\hline F & 32 & 0 & $8.000,00$ & $\begin{array}{c}\text { Ensino } \\
\text { fundamental } \\
\text { completo }\end{array}$ & $\begin{array}{c}\text { Católica } \\
\text { praticante }\end{array}$
\end{tabular}

Fonte: os autores.

Para este artigo, faremos a exposição dos resultados obtidos a partir das perguntas abertas a partir de roteiro pré-determinado com as seguintes perguntas:

Tabela 2 - Roteiro de entrevista

\begin{tabular}{l|l}
\hline 1 & O que a levou a se candidatar para o cargo de vereador no município? \\
\hline 2 & $\begin{array}{l}\text { Em sua opinião, qual a importância da participação da mulher na política de Cruzeiro } \\
\text { do Oeste? }\end{array}$ \\
\hline 3 & Você considera a participação da mulher na política local baixa? Por quais motivos? \\
\hline 4 & Como foi a sua campanha? Quais as dificuldades enfrentadas? \\
\hline 5 & Qual o apoio familiar recebido para constituir esse cenário público? \\
\hline
\end{tabular}

Fonte: os autores.

Em conformidade com a primeira questão "O que a levou a se candidatar para o cargo de vereador no município?", pode-se observar que quatro das seis candidatas aos cargos eletivos se candidataram pois viam uma ponte entre seu trabalho do dia a dia com a legislatura, sendo que trabalham na área da educação, saúde, estão presentes ações de sua igreja, tendo um contato amplo com as pessoas e seu eleitorado, sendo este assunto fundamentado adiante, além da vontade e do sonho que tinham em cuidar e lutar pelo povo. Unida a essa análise, foi observado também que uma das vereadoras teve seu incentivo na família durante a sua criação, sendo que desde pequena já frequentava comícios nas campanhas de seus familiares: 
Cresci em palanques, na época era palanques, para fazer os comícios, então eu trago na veia esse sangue político, meu avô foi vice-prefeito duas vezes, o meu pai sempre trabalhou nesse meio e depois minha mãe quis ser vereadora, foi vereadora por uma gestão, saiu candidata a prefeita e atualmente é a vice-prefeita. (Entrevistada D).

Um fato muito interessante a ser discutido, tendo em vista que atualmente no Brasil é visível a presença da instituição família no governo ou ainda o poder concentrado transitando de forma hereditária, conforme nos ensina o professor Ricardo Costa de Oliveira ${ }^{10}$ (2012). Unido a isso, é importante salientar que dentre as relações de poder o capital social está intimamente associado as inter-relações individuais e/ou do grupo em que pertence (família, associação, partido, nação...), surtindo efeito em suas contribuições sociais, como teoriza Pierre Bourdieu:

\begin{abstract}
O capital social é o conjunto de recursos atuais ou potenciais que estão ligados a posse de uma rede durável de relações mais ou menos institucionalizadas de interconhecimento e de inter-reconhecimento ou, em outros termos, a vinculação a um grupo, como conjunto de agentes que não somente são dotados de propriedades comuns (passíveis de serem percebidas pelo observador, pelos outros ou por ele mesmo), mas também são unidos por ligações permanentes e úteis. (BOURDIEU, 2014, p.75).
\end{abstract}

Desta forma, no campo da política a formação de capital social é essencial, especialmente no caso das mulheres, que devem se sobrepor às barreiras sociais que já indicamos e são facilmente observáveis na sociedade brasileira. No caso das cidades pequenas, como é o caso em tela, vemos que as circunstâncias nacionais colocam determinações nas ações e estratégias de habitus que buscam se apoiar no poder familiar - ainda que em pequena medida - para a continuidade no poder. Mesmo em regiões de recente colonização, podemos perceber que a tradição é inventada de geração a geração, ainda que infinitesimal, que irá repercutir no fenômeno do nepotismo em geral: “A importância das mulheres oriundas de famílias tradicionais é bastante importante para a recepção, a propulsão e a grande escalada de novos atores emergentes e ascensionais" (OLIVEIRA ${ }^{11}$, 2016, p. 15). Desta forma, a reprodução social do familismo é uma força presente inclusive em cidades menores e recentes.

Para além da formação do capital familiar (que implica em um esforço geracional) a formação de uma rede de contatos amplo pode influenciar também na carreira política local, como o relato de uma das entrevistadas:

Eu analiso que sempre gostei muito de gente, de estar no meio do povo, de participar das ações da igreja, ações com a comunidade, projetos que pudessem desenvolver o ambiente em

\footnotetext{
${ }^{10}$ COSTA, R. Na teia do nepotismo: sociologia política das relações de parentesco e poder político no Paraná e no Brasil. Curitiba: Insight, 2012.

${ }^{11}$ OLIVEIRA, R. Sem mulheres não há nepotismo. "Cherchez la femme" e principalmente "Cherchez la famille". Mulheres, famílias e genealogias emergentes!. In: OLIVEIRA, R. Nepotismo, Parentesco e Mulheres. 2.ed. Curitiba: Ubi et Orbi, 2016.
} 
que a gente vivia, então como eu sou de uma comunidade pequena que precisava se unir e isso foi nascendo dentro de mim. (Entrevistada F).

Conforme podemos perceber na próxima fala, a família é uma constante na vida política dos municípios menores. Embora a entrevistada anterior coloque claro sua individualidade em participar das questões sociais locais, em seu gosto por "estar no meio do povo", a participação familiar é evidente e foi influenciada desde jovem por sua família a estar engajada na política:

A minha família sempre teve engajamento filiada a partidos políticos, eu tive dois tios que foram candidatos a vereadores, mas não se elegeram, mas meus pais tiveram e têm até hoje filiação partidária. Eu sou filiada a mais ou menos 16 anos. " (Entrevistada F).

Desta forma, a pesquisa acerca da participação feminina na política, em busca da mulher real e sua percepção acerca do meio de poder brasileiro não revela apenas a mulher, mas também pode desvelar o homem e seu comportamento na política, e como as famílias também, enquanto unidade de cultivo do poder político se comporta em relação aos cargos eletivos, ainda que estejamos investigando situações como a de Cruzeiro do Oeste.

No decorrer da entrevista foi questionado também as outras mulheres, se viam na família alguma influência ou incentivo para hoje estarem participando deste meio e segundo uma delas, por mais que seus pais não tinham estudo, eram ainda muito engajados nas questões políticas da sociedade, como podemos perceber na fala de uma vereadora que também é professora:

\footnotetext{
Meus pais eram analfabetos, mas pais assim sabe que diziam: Vão estudar, quero vocês sabendo ler e a escrever, tendo a enxada como caneta, mas essa enxada e essa caneta tem um peso muito grande para mim, é de muito valor essa caneta chamada enxada, quando você me pergunta se houve alguma influência, eu digo que sim, porque a minha mãe mesmo sendo analfabeta ela é muito política, minha mãe ela é muito dada dentro da igreja, muito dada dentro da comunidade, muito dada dentro do trabalho, então houve sim um incentivo. (Entrevistada C).
}

Fica nítido que mesmo que a família não esteja diretamente envolvida com a política partidária ou estatal, a formação da mulher na política acontece em casa, com familiares que valorizem tanto a educação formal, embora sejam analfabetos. Além disso, o exemplo da mãe que tinha um envolvimento social reconhecido na comunidade religiosa (cujas ações são consideradas como "políticas") são fatores essenciais para a formação e incentivo político da participação em municípios menores. 
Referindo-se a segunda questão, "Em sua opinião, qual a importância da participação da mulher na política de Cruzeiro do Oeste? ", é visível a presença de estereótipos em suas falas, como a sensibilidade, o afeto, o amor, entre outros.

\begin{abstract}
Acredito que uma boa política para nossos representantes realmente representar a nossa comunidade ela tem que ser diversificada e a mulher é essencial, porque a mulher é a cabeça da casa, a mulher além de ter o conhecimento cientifico, ela também tem o conhecimento do dia a dia, aquela prática amorosa com o filho, com a família, mais sensível. (Entrevistada D).
\end{abstract}

Percebemos que está presente no discurso que a mulher é essencial na política por conta do seu papel na casa, que, além de exercer um papel "racional", administrativo, tal papel está relacionado com o sentimento, especialmente o amor aos filhos. A mulher na política significaria um equilíbrio necessário com o domínio masculino, como se a boa política resultasse do equilíbrio entre o masculino e o feminino, a rua (o trabalho) e a casa (o doméstico). Com certeza, em cidades menores, tal discurso é bastante forte, devido à proximidade da sociedade, e de uma definição de papéis que acompanha a condição sexual. Em outra fala, podemos perceber tal tendência:

Eu acredito que a mulher na política local e a mulher em várias classes da sociedade em si, nos grupos, nas entidades filantrópicas, traz um olhar diferenciado, porque a mulher é sensível a mais que o homem por natureza, é da mulher, então isso traz um olhar diferenciado, um olhar que talvez no contexto masculino não teria. Em alguns momentos isso tem mais a ser positivo do que negativo, em termos emotivos isso pode ser prejudicial, mas no contexto geral o olhar daquela que gera, que cuida, que é mãe, tudo isso é muito salutar, é diferente, os homens eles realmente são o carro chefe na política e nós mulheres, junto com eles tendo esse olhar diferenciado, soma. (Entrevistada E).

Observamos a naturalização da mulher, presente mais uma vez no discurso da mulher política. No entanto, podemos perceber que para esta vereadora o homem é realmente o "carro chefe" da política, uma vez que o excesso de sentimentalismo da mulher seria, enfim, mais negativo que positivo, especialmente na condução da política. A mulher seria uma "soma" para a política, mas claro, em devidas proporções. A questão do sentimento também aparece na seguinte fala:

Na minha opinião é necessário, a mulher trabalha muito o coração, quando existe a razão (homem) chega a mulher com razão mais coração. Eu acho que pelo fato e Deus ter dado a dadiva de gerar o coração fala alto. (Entrevistada C).

É comum ver em discursos midiáticos ou até mesmo no pensamento popular essa diferenciação entre o homem e a mulher, tendo em vista que estes estereótipos vêm de berços culturais, capaz de estabelecer características sobre um grupo de pessoas a fim de diferencia-lo dos 
demais. Segundo Aronson ${ }^{12}$ (2004, apud PANKE e IASULAITIS 2016, p. 388), estereotipar é "atribuir" características idênticas a qualquer pessoa integrante de um grupo, independente da real variação que há dentre os membros desse grupo. Sendo essa a maior objeção em dizer que por conta de a mulher ser mais sensível, dona da casa e amorosa irá trazer um "equilíbrio", dizendo assim, para a sociedade, sendo que na verdade este é um estereotipo que pode não ser adequado a diferentes pessoas desse mesmo grupo. De acordo com Panke \& Iasulaitis (2016), a mulher candidata deve fazer um uso estratégico de sua condição feminina, o que parece se repetir no caso da mulher que exerce cargo político também.

Ao perguntar para as mulheres ocupantes dos cargos se consideravam a participação local baixa com a questão "Você considera a participação da mulher na política local baixa? Por quais motivos?", se manifestaram com muita alegria, refutando que a participação local é ótima, haja vista de que é a primeira vez na história da cidade que este fato acontece, tendo mais de duas mulheres vereadoras dentro da câmara de vereadores. Pudemos perceber um "mascaramento" em relação ao histórico da participação da mulher na política local. Como foram eleitas 5 mulheres, um índice muito expressivo até mesmo para a região (Umuarama, cidade próxima, distante cerca de 30 quilômetros de Cruzeiro do Oeste, e com cerca de 100 mil habitantes, teve 2 mulheres eleitas para sua Câmara), este fato parece "apagar" o passado da cidade, quando havia muita dificuldade para a eleição de uma representante feminina. Vejamos a fala:

"Não, muito pelo contrário, a participação da mulher aqui na nossa câmara de vereadores é muito atuante, ela está muito na alta, até porque quando ocorreu a eleição de quatro mulheres, simplesmente a cidade movimentou conosco”. (Entrevistada C).

Um ponto muito importante que deve ser levado em consideração, é o fato de que a cidade movimentou com as candidatas, o que aparece no relato de todas as eleitas, que a população efetivamente deu crédito para a eleição de suas representantes, até mesmo "vibrando e incentivando", o que é um avanço grandioso na sociedade, talvez por ser uma cidade menor e "onde todos se conhecem" como é a fala comum. Elas evidenciam que não só tiveram o apoio da população na campanha e atualmente no mandato como também tem dos companheiros vereadores, que tem um respeito imenso com todas, dizem que foram muito bem recebidas por eles e hoje trabalham em união, sendo incentivadas por eles.

\footnotetext{
12 PANKE, L. \& IASULAITIS, S. Mulheres no poder: aspectos sobre o discurso feminino nas campanhas eleitorais. Opin. Publica, Campinas, v. 22, n. 2, p. 385-417, Aug. 2016.
} 
Podemos observar também na fala da representante do Executivo local que a baixa participação feminina implica também em desvalorização das políticas voltadas para as mulheres:

\begin{abstract}
Vou responder de duas maneiras; na minha época era baixa, quando eu fui vice prefeita não tinha nenhuma mulher como vereadora e eu a primeira vice prefeita de Cruzeiro do Oeste mulher, em 60 e poucos anos de história, então naquele momento era extremamente baixa a participação das mulheres na política, o que nos enfraquecida, porque muitas vezes eu levava para o executivo alguns projetos, algumas leis para mulheres e com a visão totalmente masculina, a gente acabava em desvantagem na hora de votar um projeto, na hora de defender, porque os homens as vezes pensavam mais na questão econômica, na questão mais prática, na questão que vai atingir mais a população geral e então no meu momento, na minha gestão como você prefeita era realmente muito baixa. (Entrevistada F).
\end{abstract}

Percebemos que a participação feminina é essencial para uma representação democrática e igualitária dos gêneros nos meios políticos e de gestão pública. Podemos também observar a tendência histórica, discutida em nossa introdução, que governos masculinizados prezam por questões gerais, racionais e econômicas, o que muitas vezes vai de encontro às necessidades da parcela feminina da população - que muitas vezes corresponde também à maior parte da população. Observamos, portanto, que não há uma consciência real a respeito da participação feminina na política, pois a mesma está condicionada com a época política, sendo mais ou menos favorável à participação da mulher nos meios públicos, de acordo com as circunstâncias eleitorais.

Foi questionado as dificuldades da campanha através da questão "Como foi a sua campanha? Quais as dificuldades enfrentadas?", se sentiram mesmo que indiretamente a presença do machismo e como dito anteriormente, todas alegaram que não, muito pelo contrário, tiveram um apoio grandioso por onde passavam, claro que era limitado os lugares que podiam ir sozinhas, mas sempre foram incentivadas até mesmo pelos homens.

Dificuldades em ser mulher que eu encontrei, ambientes em que eu não podia ir sozinha, na questão física mesmo, mas as reuniões nas casas eram todas maravilhosas, fui muito bem recebida sempre, mas alguns lugares você tem a vulnerabilidade pela questão do receio físico mesmo, por conta do descrédito da política faz com que o agente político seja visto com maus olhos, ainda mais uma mulher, mas isso aconteceu muito pouco, pois sempre andávamos em grupos então nessa parte foi bem positivo. (Entrevistada E).

Aqui é dito algo muito importante, existe um descrédito da política, que é natural, existente na sociedade, portanto a campanha política já deixa essas pessoas vulneráveis, quando se vê então uma mulher participando deste meio, traz um desconforto ainda maior para essas pessoas, que vê esse agente político com maus olhos. Interessante o apontamento a respeito dos ambientes que uma mulher "não pode ir sozinha", considerando o discurso que em uma cidade pequena há um certo pacifismo pois "todos se conhecem", e considerando que se trata de uma representante política do Estado brasileiro, que deve também zelar pelo direito de "ir e vir" de todos os cidadãos. 
Mesmo esta participação ter sido incentivada, houveram ainda mesmo que indiretamente como dito acima preconceitos e opressões, como:

Não, não sentimos diferença em tratamento, apesar de que quando se tratava da presidência da câmara a mulher servia para ser primeira secretária, tesoureira, mas não presidente, a cabeça era o homem, aí sim, nessa área imperou o machismo. (Entrevistada A)

\section{Em relação à pergunta "Qual o apoio familiar recebido para constituir esse cenário} público?" Através desta pergunta, pudemos confirmar o que já foi dito acima: que a família importa, não apenas no sentido do apoio material e sentimental no período das eleições, mas sim na formação e na orientação para a busca dos cargos eletivos, ainda que em contextos de municípios menores e em famílias que ainda constroem sua tradição.

\footnotetext{
Eu tive o apoio da minha família, eu tive o apoio do meu esposo, apoio dos meus pais, e também dos meus filhos. Casei com uma pessoa que o pai fazia parte da política, mas o que me deu essa bagagem de estar na política foi pelo meu ideal de querer representar a mulher, a educação, e meu marido foi muito forte na minha decisão porque ele já fazia parte da política, já havia coordenado algumas campanhas para o município de Cruzeiro do Oeste e ele sempre me colocou com os pés no chão, então eu conheci mais da política pela família do meu sogro. (Entrevistada D).
}

Podemos assim perceber que o casamento é também uma forma de estratégia para o capital social da política. Talvez não tenha a força dos casamentos de famílias tradicionais na política, mas temos aqui elementos que indicam que mesmo no contexto local o matrimônio é também meio de conquistar posições estratégicas nos cargos políticas, como atalhos para campanhas e em cargos de secretarias, que acabam por dar destaque aos agentes.

Ressaltando como dito anteriormente no objetivo deste trabalho sendo analisar os fatores que influenciam na participação feminina na câmara de Cruzeiro do Oeste, tem-se como presunção o fato da população da cidade não apresentar fortes resquícios de machismo entre outros preconceitos, capazes de afastar as mulheres deste meio que é a política, tendo em vista que tem muito a somar junto aos homens e a população. Um outro fator que também pode influenciar na eleição dessas quatro mulheres é a atuação religiosa, sendo quatro delas praticantes e bem vistas dentro das mesmas.

\section{Considerações finais}

Podemos dizer que a atual luta democrática em nosso país é a luta pela representatividade, e a mulher tem papel essencial neste processo. A mulher representa 52,290\% do eleitorado nacional, mas "Na América Latina, o Brasil é o segundo país com menor índice de mulheres em cargos 
legislativos federais. Apenas 9,9\% dos deputados federais. A média nas Américas é de 22\%, sendo que a Argentina e a Costa Rica são destaques, com 38\% cada. " (FERRICHE \& MACÁRIO $\left.{ }^{13}, 2014\right)$. Temos ainda, $13 \%$ de Senadoras. Um número que coloca o Brasil como a 116. Posição em ranking internacional de representação feminina no legislativo, entre 190 países $\left(\mathrm{CHADE}^{14}\right.$, 2015). Uma realidade que sequer condiz com a nova configuração familiar brasileira, onde mulheres já chefiam cerca de $40 \%$ de lares brasileiros. (PORTAL BRASIL ${ }^{15}, 2015$ ).

Assim sendo, podemos apontar que a falta de representatividade feminina na política ainda assombra a cultura brasileira. E se é uma questão de cultura, nossa singela contribuição com este projeto é o questionamento acerca de como a mulher em cargo eletivo local se sente no seu cargo. Pretendemos aqui investigar não o lado do eleitor, mas a representação social e a percepção da mulher que ocupa o cargo político, após passar pelo processo eletivo.

Finalmente, devemos destacar a relevância social desta análise. Já apontamos alguns números que revelam que no campo da representatividade feminina o Brasil ainda está em déficit. Nosso artigo pode contribuir com a formação de uma consciência mais democrática e representativa, tanto por parte dos futuros eleitores, quanto por parte das mulheres que corajosamente já se lançam aos cargos locais.

\section{Referências Bibliográficas}

BARBOSA GOMES, J. (S.D.) O debate constitucional sobre as ações afirmativas. Londrina-PR: Agência UEL de Notícias, s.d. Disponível em: <http://www.uel.br/com/noticiadigital/index.php?arq=ARQ_art\&FWS_Ano_Edicao=1\&FWS_N_E dicao =1\&FWS_Cod_Categoria=1\&FWS_N_Texto=3529>. Acesso em: 15/09/2017.

BOURDIEU, P. A dominação masculina. 8.ed. Rio de Janeiro: Bertrand Brasil, 2010.

CHADE, J. (2015). Brasil tem menos mulheres no Legislativo que Oriente Médio. Jornal Estadão online, 06/03/2015. Disponível em: < http://politica.estadao.com.br/noticias/geral,brasil-tem-menosmulheresno-legislativo-que-oriente-medio,1645699 >. Acesso em: 20/03/2018.

COSTA, A. As donas no poder. Mulher e política na Bahia. Salvador: NEIM/UFBa - Assembleia Legislativa da Bahia, 1998. Col. Bahianas. Disponível em <http://www.neim.ufba.br/site/arquivos/file/donasnopoder.pdf>. Acesso em: 28/02/2018.

\footnotetext{
${ }^{13}$ FERRICHE, E. \& MACÁRIO, L. Estudo analisa nova composição da Câmara por gênero e raça. Rádio Câmara, Com a Palavra, 09/10/2014. Disponível em: < http://www2.camara.leg.br/camaranoticias/radio/materias/COM-APALAVRA/475678-ESTUDOANALISA-NOVA-COMPOSICAO-DA-CAMARA-POR-GENERO-E-RACA.html > . ${ }^{14}$ CHADE, J. (2015). Brasil tem menos mulheres no Legislativo que Oriente Médio. Jornal Estadão on-line, 06/03/2015. Disponível em: <http://politica.estadao.com.br/noticias/geral,brasil-tem-menos-mulheresno-legislativo-que-orientemedio, 1645699>.

${ }^{15}$ PORTAL BRASIL. Mulheres comandam 40\% dos lares brasileiros. Governo do Brasil, Cidadania e Justiça, 2015.
} 
ENGELS, F. A origem da família, da propriedade privada e do Estado. In: MARX, K. \& ENGELS, F. Obras escolhidas. São Paulo: Alfa Ômega, s.d. Vol. 03.

FERRICHE, E. \& MACÁRIO, L. Estudo analisa nova composição da Câmara por gênero e raça. Rádio Câmara, Com a Palavra, 09/10/2014. Disponível em: <http://www2.camara.leg.br/camaranoticias/radio/materias/COM-A-PALAVRA/475678ESTUDOANALISA-NOVA-COMPOSICAO-DA-CAMARA-POR-GENERO-E-RACA.html> . Acesso em: 20/03/2018.

HARAWAY, D. Gênero" para um dicionário marxista: a política sexual de uma palavra. Cad. Pagu, Campinas, n. 22, p. 201-246, 2004.

NOGUEIRA, M \& CATANI, A. Escritos da educação: O capital Social; Os três estados do capital cultural. 15. Ed. Petrópolis, RJ: Vozes, 2014.

OLIVEIRA, R. Na teia do Nepotismo: sociologia política das relações de parentesco e poder político no Paraná e no Brasil. Curitiba/PR: Insight, 2012.

OLIVEIRA, R. Sem mulheres não há nepotismo. "Cherchez la femme" e principalmente "Cherchez la famille". Mulheres, famílias e genealogias emergentes!. In: OLIVEIRA, R. Nepotismo, Parentesco e Mulheres. 2.ed. Curitiba: Ubi et Orbi, 2016.

PANKE, L. \& IASULAITIS, S. Mulheres no poder: aspectos sobre o discurso feminino nas campanhas eleitorais. Opin. Publica, Campinas, v. 22, n. 2, p. 385-417, Aug. 2016.

PORTAL BRASIl. Mulheres comandam $40 \%$ dos lares brasileiros. Governo do Brasil, Cidadania e Justiça, 2015.

REED, E. Sexo contra sexo ou classe contra classe. São Paulo: Editora Instituto José Luís e Rosa Sundermann, 2008.

VAZ, G.A. A participação da mulher na política Brasileira: a lei de cotas. Monografia de Conclusão de Curso apresentada ao Curso de Especialização em Processo Legislativo do Centro de Formação, Treinamento e Aperfeiçoamento, da Câmara dos Deputados. 2008. 